\title{
Contemporaneous comparison of the Yasui and Norwood procedures at a single institution
}

\author{
Sergio A. Carrillo, MD, ${ }^{a}$ Richard D. Mainwaring, MD, ${ }^{a}$ Justin M. Schaffer, MD, ${ }^{a}$ Gail Wright, MD, ${ }^{b}$ \\ Katsuhide Maeda, MD, ${ }^{a}$ Frank L. Hanley, MD, ${ }^{a}$ and V. Mohan Reddy, MD
}

Objective: It is recognized that there are numerous anatomic variants that result in hypoplastic left heart
physiology. One such variant includes critical aortic stenosis or atresia, a hypoplastic aortic arch, and a
reasonably well-developed left ventricle due to the presence of a ventricular septal defect. These patients are
candidates for 1 of 3 surgical options: (1) a Norwood procedure followed by a single-ventricle pathway; (2) a
Norwood procedure followed by a Rastelli procedure (2-stage Yasui); or (3) a single-stage Yasui procedure.
Because 2 of the 3 options include a Norwood procedure as the initial step, the purpose of this study was to
evaluate the contemporaneous results of the Yasui and Norwood procedures at a single institution.

Methods: This was a retrospective review of patients who underwent a Yasui or Norwood procedure at Lucile Packard Children's Hospital between 2004 and 2013. Eighteen patients underwent a Yasui, of whom 15 had a single-stage procedure and 3 had a 2 -stage procedure. During this time frame, 113 patients underwent a Norwood procedure. Kaplan-Meier survival curves and freedom from reoperation were compared for the 2 procedures.

Results: The operative mortality (using the Society of Thoracic Surgeons definition) for the single-stage Yasui was $6.7 \%$ compared with $16 \%$ for the Norwood procedure $(P<.05)$; survival was $85 \%$ versus $62 \%$ at 1 year, $85 \%$ versus $60 \%$ at 3 years, and $85 \%$ versus $58 \%$ at 5 years, respectively (log-rank $P=.06$ ). The average interval to first reoperation was $13.5 \pm 3$ months versus $4.5 \pm 1$ months for the Yasui and Norwood procedures, respectively $(P<.001)$.

Conclusions: The Yasui procedure had a significantly lower operative mortality compared with the Norwood procedure. Early and midterm survival was also higher in the Yasui group versus the Norwood followed by a single ventricle pathway. These results indicate that the Yasui procedure has significant midterm benefits compared with the Norwood procedure and should be pursued when the anatomy is amenable for this approach. (J Thorac Cardiovasc Surg 2015;149:508-13)

See related commentary on page 514 .

It is recognized that there are many anatomic variants that can result in hypoplastic left heart physiology. One variant includes critical aortic stenosis or atresia, a hypoplastic or interrupted aortic arch, and a reasonably well-developed, apex-forming left ventricle due to the presence of a ventricular septal defect (VSD). There are 3 potential reconstructive options for patients with this anatomy. One possibility is to perform a Norwood procedure followed

From the Divisions of Pediatric Cardiac Surgery ${ }^{\mathrm{a}}$ and Pediatric Cardiology, ${ }^{\mathrm{b}}$ Lucile Packard Children's Hospital/Stanford University, Stanford, Calif.

Disclosures: Authors have nothing to disclose with regard to commercial support.

Read at the 40th Annual Meeting of The Western Thoracic Surgical Association, Dana Point, California, June 25-28, 2014.

Received for publication June 12, 2014; revisions received Sept 1, 2014; accepted for publication Sept 27, 2014; available ahead of print Nov 6, 2014

Address for reprints: Richard D. Mainwaring, MD, Stanford University School of Medicine, 300 Pasteur Drive, Falk CVRC, Stanford, CA 94305 (E-mail: mainwaring@stanford.edu).

$0022-5223 / \$ 36.00$

Copyright (c) 2015 by The American Association for Thoracic Surgery

http://dx.doi.org/10.1016/j.jtcvs.2014.09.120 by a single-ventricle pathway. A second option is to perform a Norwood procedure as the initial step followed by a Rastelli procedure. The third option is to perform a single-stage Norwood/Rastelli procedure. The strategy of creating a 2-ventricle repair for this anatomy was first proposed by Yasui and colleagues ${ }^{1}$ in 1987 and has subsequently carried this eponym. ${ }^{2}$

The relative merits of the Yasui procedure can best be judged in the context of the alternative options that would exist for these patients. The Yasui procedure is a complex operation performed in young patients and consequently is associated with significant morbidity and mortality. A review of the literature would indicate an operative mortality of approximately $9 \%$ for the Yasui procedure. ${ }^{3-8}$ However, it does have a theoretic advantage compared with a Norwood single-ventricle approach for 2 important physiologic reasons. First, a 2-ventricle repair results in normalization of the circulation (ie, Qp:Qs $=1$ ). The Yasui repair also results in fully saturated blood going to the systemic circulation. In contradistinction, the Norwood procedure creates a "parallel circulation," which has proven to be a far more tenuous physiology. Patients undergoing a Norwood procedure for hypoplastic left heart 


\section{Abbreviation and Acronym \\ VSD $=$ ventricular septal defect}

physiology have had significantly worse outcomes than for all other forms of single ventricle, and despite many improvements in the management and care over the past 20 years, have continued to experience a high early and interim mortality. ${ }^{9}$ Because 2 of the 3 surgical options for aortic stenosis or atresia, interrupted or hypoplastic aortic arch, VSD, and an apex-forming left ventricle include an initial Norwood procedure, these patients by definition are exposed to this early period of vulnerability.

Our surgical group has pursued a single-stage, 2-ventricle approach for patients with critical aortic stenosis or atresia, a hypoplastic aortic arch, VSD, and a normal-sized left ventricle. This is based on the belief that a 2 -ventricle circulation will be more durable than a single-ventricle physiology. The purpose of this study was to perform a contemporaneous comparison of the Yasui and Norwood procedures at Lucile Packard Children's Hospital.

\section{MATERIALS AND METHODS}

This was a retrospective review of patients who underwent a Yasui or Norwood procedure at Lucile Packard Children's Hospital between 2004 and 2013. The study was approved by the institutional review board at Stanford University. Patients were identified through the cardiac database, and the medical records were subsequently reviewed.

Eighteen patients underwent a Yasui procedure during this 10-year time period. Fifteen of the 18 patients had a single-stage approach. The average age at surgery for these 15 patients was $2.5 \pm 1.0$ weeks, with an average weight of $3.6 \pm 0.5 \mathrm{~kg}$. The 15 neonates who underwent a single-stage Yasui will comprise the cohort to be compared statistically with the Norwood cohort.

Three patients underwent a 2-stage approach, in which the initial stage (Damus/arch reconstruction) was performed at an outside institution. These 3 patients were subsequently referred to Lucile Packard Children's Hospital to evaluate the possibility of conversion to a Yasui, because they had a relatively normal-sized and apex-forming left ventricle. These 3 patients underwent a Rastelli procedure at our institution at an average age of $17 \pm 8$ months and weight of $8.5 \pm 2.5 \mathrm{~kg}$. Although these 3 patients are described in this overall operative experience, they are excluded from the statistical analysis because they did not receive their neonatal operation at our institution. For these 3 patients, there were no early or late deaths after the Rastelli procedure.

The echocardiographic findings of the 18 patients who underwent a Yasui procedure are summarized in Table 1. Eight of the 18 patients had aortic atresia, and 10 patients had critical aortic stenosis. For the 10 patients who had a patent aortic valve, the average $z$ score was a minus $4.1 \pm 1.2$. Ten of the 18 patients had an interrupted aortic arch. The average $z$ score for the left ventricle (as assessed by measurement of left ventricular end diastolic dimension) was a negative $1.7 \pm 0.9$.

The typical anatomy of patients who underwent a Yasui procedure is shown in Figure 1, A. Externally, there is a diminutive ascending aorta with a hypoplastic transverse arch. The pulmonary trunk is enlarged, particularly with respect to the aorta. The coronary artery pattern is normal, with the left anterior descending coronary delineating the position of the interventricular septum.
The Yasui procedures were performed through a median sternotomy using cardiopulmonary bypass and antegrade cerebral perfusion for the arch repair portion of the procedure. ${ }^{10}$ We perform direct cannulation of the innominate artery for arterial perfusion and add a second cannula in the ductus arteriosus if there is an interrupted aortic arch or severe transverse arch hypoplasia. Bicaval venous cannulation is used for venous drainage, and a left ventricular vent catheter is inserted through the right superior pulmonary vein.

Cardiopulmonary bypass was instituted with flow rates between 125 and $150 \mathrm{~mL} / \mathrm{kg} / \mathrm{min}$. The patients were cooled to $20^{\circ} \mathrm{C}$, and ice was placed around the head. The aortic arch, head and neck vessels, and proximal descending thoracic aorta were fully mobilized, as were the main and branch pulmonary arteries. Antegrade cerebral perfusion was then implemented with flow rates decreased to 40 to $50 \mathrm{~mL} / \mathrm{kg} / \mathrm{min}$. The pulmonary trunk was divided proximal to the bifurcation of the right and left branch pulmonary arteries, and the ductus arteriosus was ligated and divided. The aortic arch reconstruction was performed using pulmonary allograft patch augmentation. The proximal pulmonary trunk was sutured to the proximal incision on the ascending aorta, and the reconstruction was completed by bringing the homograft patch onto the proximal ascending aorta and pulmonary trunk (Figure 1,B). After completion of the arch repair, full flow was resumed for the remainder of the operation.

A right ventriculotomy was then performed, and the location of the VSD was inspected (Figure 1, C). An autologous pericardial patch treated with $0.9 \%$ glutaraldehyde was fashioned to channel the VSD to the neoaortic pulmonary valve (Figure 2, A). Two patients required enlargement of the VSD because of the relatively small size of the defect. A secundum type atrial septal defect or patent foramen ovale was repaired. The aortic crossclamp was then removed, and rewarming was instituted while the remainder of the procedure completed.

Continuity from the right ventricle to the branch pulmonary arteries was established with the use of an aortic allograft valved conduit (Figure 2, B). The conduit sizes for the 18 patients undergoing the Yasui are shown in Table 2. The proximal connection was augmented with an additional patch to avoid distortion of the allograft valve. The completed repair is shown in Figure 2, $C$.

During this same 10-year time frame, 113 patients underwent a Norwood procedure at Lucile Packard Children's Hospital. A total of 111 of the 113 patients $(98 \%)$ had the Sano modification of the Norwood procedure using a right ventricle to pulmonary artery valved conduit. These 113 patients provide the substrate for comparison of the Yasui procedure with the Norwood procedure. None of the 113 patients who underwent a Norwood had a sufficient left ventricular size that would have been amenable for a Yasui procedure.

Statistical results are reported as the mean \pm standard deviation. The primary end point was mortality, with censoring at the time of most recent follow-up. Kaplan-Meier curves were constructed with the STATA software package (version 13, StataCorp LP, College Station, Tex). The Kaplan-Meier curves were compared with the rank test. Specific temporal points were compared using chi-square analysis. Freedom from reoperation was evaluated using an actuarial estimate with censoring at death. ${ }^{11}$

\section{RESULTS}

Fifteen patients underwent a single-stage Yasui operation, with $1(6.7 \%)$ operative mortality. This patient underwent a single-stage Yasui procedure at 4 weeks of age, but multisystem organ dysfunction developed and the patient died 2 months postoperatively without leaving the hospital (thus fulfilling the Society of Thoracic Surgeons Congenital Heart Surgery definition as an operative mortality). A second patient died 11 months postoperatively, who initially had undergone a single-stage 
TABLE 1. Echocardiographic measurements

\begin{tabular}{cccccc}
\hline $\begin{array}{c}\text { Patient } \\
\text { no. }\end{array}$ & $\begin{array}{c}\text { LVEDD } \\
(\mathbf{m m})\end{array}$ & $\begin{array}{c}\text { LVEDD } \\
\boldsymbol{z} \text { score }\end{array}$ & $\begin{array}{c}\text { LVOT } \\
\boldsymbol{z} \text { score }\end{array}$ & $\begin{array}{c}\text { Aortic valve } \\
\boldsymbol{z} \text { score }\end{array}$ & $\begin{array}{c}\text { Ascending } \\
\text { aorta }(\mathbf{m m})\end{array}$ \\
\hline 1 Stage & & & & & \\
1 & 1.68 & -1.7 & -7 & Atresia & 2.0 \\
2 & 1.65 & -1.1 & -4 & -4 & 3.8 \\
3 & 1.78 & -0.9 & -7 & -7 & 3.0 \\
4 & 1.88 & 0.5 & -7 & Atresia & 1.7 \\
5 & 1.70 & -1.5 & -6 & -6 & 6.0 \\
6 & 1.59 & -2.0 & -7 & Atresia & 5.3 \\
7 & 1.78 & -1.1 & -5 & -5 & 6.5 \\
8 & 1.64 & -1.7 & -4 & -3 & 5.7 \\
9 & 1.35 & -2.9 & -5 & -5 & 5.3 \\
10 & 1.58 & -0.7 & -7 & Atresia & 2.0 \\
11 & 1.29 & -3.7 & -7 & Atresia & 3.0 \\
12 & 1.77 & 1.2 & -7 & Atresia & 2.5 \\
13 & 1.52 & -2.8 & -4 & -4 & 6.0 \\
14 & 1.42 & -2.1 & -7 & Atresia & 3.7 \\
15 & 1.68 & -1.7 & -4 & -4 & 6.0 \\
2 Stage & & & & & \\
16 & 1.77 & -3.5 & -5 & Atresia & 2.9 \\
17 & 2.01 & -0.6 & -4 & -3 & 3.5 \\
18 & 2.56 & -3.0 & -4 & -4 & 3.7 \\
\hline
\end{tabular}

LVEDD, Left ventricular end-diastolic dimension; LVOT, left ventricular outflow tract.

Yasui at 10 days of age. The patient returned 7 months later with evidence of arch obstruction and depressed left ventricular function. The patient underwent re-repair of the aortic arch, but failed to demonstrate an improvement in ventricular function. A Berlin Heart (Berlin, Germany) was inserted for ventricular support at 9 months of age, but recurrent episodes of sepsis developed and the patient died 2 months later. For the remaining 14 survivors, the average duration of follow-up has been $4.3 \pm 1.1$ years. Heart block developed in 2 patients after the Yasui, and they required implantation of permanent pacemakers.

The average duration of cardiopulmonary bypass for the 15 single-stage Yasui procedures was $145 \pm 25$ minutes (range, 105-185 minutes), and the average duration of aortic crossclamp was $80 \pm 20$ minutes (range, 60-104 minutes). The period of antegrade cerebral flow during the aortic repair averaged $42 \pm 15$ minutes (range, 30-64 minutes). The average size of the right ventricle to pulmonary artery allograft conduit was $10 \pm 1 \mathrm{~mm}$ (range, $8-12 \mathrm{~mm}$ ), and the average $z$ score for these implanted conduits was positive $1.4 \pm 0.7$.

The Kaplan-Meier survival curve comparing the Yasui procedure with the Norwood procedure is shown in Figure 3. The operative mortality for the Yasui procedure $(1 / 15$, or $6.7 \%)$ was statistically lower than the operative mortality for the Norwood procedure (18/113, or $16 \%$ ), $(P<.05$ compared with Yasui group). The 1-year survival for the Yasui and Norwood procedures was $85 \%$ versus
$62 \%$, the 3 -year survival was $85 \%$ versus $60 \%$, and the 5 -year survival was $85 \%$ versus $58 \%$, respectively (log rank $P=.06$ ).

The freedom from reoperation is shown in Figure 4. The average interval between the first surgical procedure and the subsequent operation was $12.5 \pm 3$ months for the Yasui and $4.5 \pm 1$ months for the Norwood $(P<.001)$. Nine patients in the Yasui group have subsequently undergone conduit replacements, and 1 patient underwent arch revision. In the Norwood cohort, 84 patients had a bidirectional Glenn procedures and 1 patient required a pulmonary vein procedure. Forty-one of the patients who had a bidirectional Glenn have subsequently undergone Fontan completion. One patient underwent heart transplantation 1 year after the Norwood and 7 months after the bidirectional Glenn. There was 1 late death after Fontan completion.

\section{DISCUSSION}

This article summarizes a contemporaneous experience with the Yasui and Norwood procedures at a single institution. The operative mortality for the Yasui cohort was $6.7 \%$ compared with $16 \%$ for the Norwood cohort. Kaplan-Meier survival curves demonstrated a survival trend in favor of the Yasui procedure. Freedom from reoperation was also superior in the Yasui cohort. Although it is recognized that the underlying anatomy of the patients in these 2 groups is dissimilar, the results provide a context to evaluate the single-stage, 2-ventricle Yasui strategy compared with the Norwood single-ventricle strategy.

Eight of the 15 patients who underwent a single-stage Yasui procedure had the anatomic diagnosis of interrupted aortic arch with VSD. These patients were not deemed suitable candidates for a standard interrupted arch/VSD repair because of the presence of severe left ventricular outflow tract stenosis in conjunction with diminutive aortic valve sizes $(z$ scores -3 to -7$)$. We have used a guideline that the measurement of the subaortic area and valve (in millimeters) must be greater than or equal to the weight of the patient (in kilograms) to proceed with a standard interrupted aortic arch repair. This guideline is consistent with the literature demonstrating that patients with aortic valve $z$ scores of -3 or less do poorly with arch repair and VSD closure. ${ }^{12-16}$ For patients with measurements below these criteria, an alternative strategy must be used to provide an unobstructed pathway from the left ventricle to the aorta. ${ }^{17,18}$ These patients are well suited for a Yasui approach, which uses the pulmonary valve as the systemic semilunar valve.

The need for reoperation in patients undergoing the Yasui procedure was primarily related to the small-sized conduits that were implanted in newborns and young infants undergoing a single-stage Yasui. ${ }^{19-21}$ For the 14 survivors of the single-stage Yasui procedure in our study, the average 

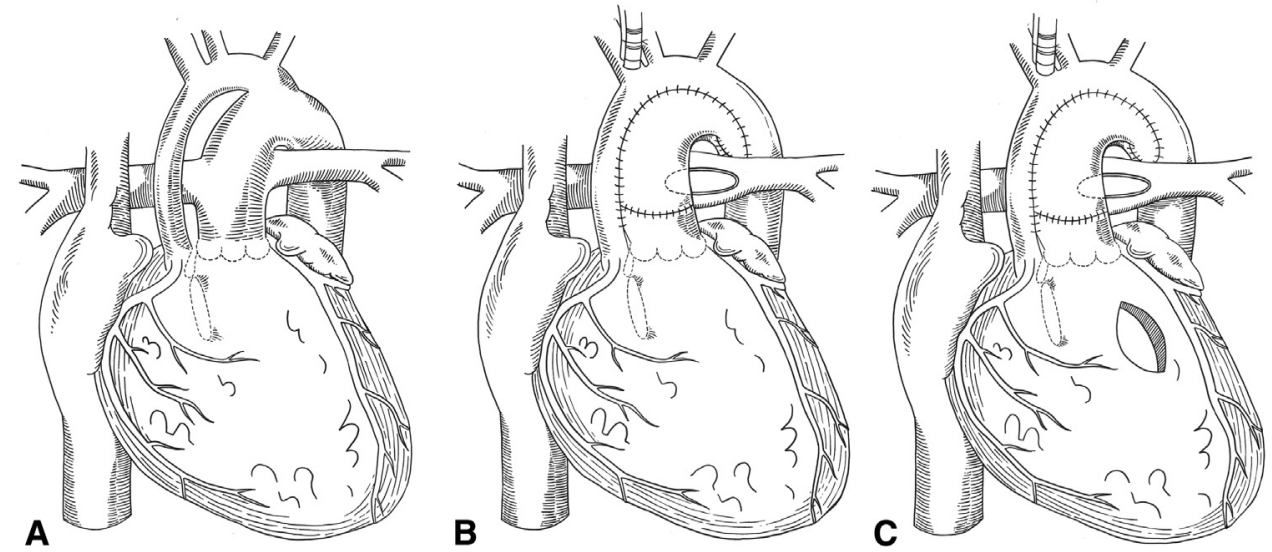

FIGURE 1. A, Critical aortic stenosis, severe hypoplasia of the transverse aortic arch, VSD, and a well-developed, apex-forming left ventricle. The position of the VSD is shown. B, Arterial cannulation strategy for aortic arch reconstruction. The innominate artery is directly cannulated, and a second arterial would be placed in the ductus arteriosus if there is interruption of the aortic arch. The patient is cooled to $20^{\circ} \mathrm{C}$, and antegrade cerebral perfusion is used during the aortic arch reconstruction. C, Right ventriculotomy and identification of the location of the VSD and its relative position to the pulmonary valve. Illustrations created by Erin Anne Mainwaring.

conduit longevity was only 13 months. Five of these 14 patients have subsequently undergone a second conduit replacement during the follow-up period. This is clearly a disadvantage of the Yasui approach, with the important caveat that the subsequent conduit replacements were performed without mortality.

Frequent reoperations for conduit replacements have been cited as an important drawback to the Yasui procedure. However, patients who had a Norwood procedure and single-ventricle pathway underwent earlier reoperations than the Yasui group. This was a consequence of the 3 -stage approach that is currently used for patients with single ventricles and of the limited longevity of the Sano right ventricle to pulmonary artery conduits that were used. During the follow-up period, 84 patients underwent a bidirectional Glenn procedure at an average of 4.5 months after the
Norwood procedure. Within this cohort, 41 patients have subsequently undergone Fontan completion at an average of 3.5 years after the bidirectional Glenn. Patients undergoing a Norwood procedure in anticipation of a 2-stage Yasui (ie, Norwood/Rastelli) will also require relatively early reoperation because of the limited longevity of the right ventricle to pulmonary artery conduits. Thus, although the Yasui procedure obligatorily commits patients to multiple conduit reoperations, viewed in the context of the reoperation rate for the Norwood/single-ventricle or Norwood/Rastelli pathway, the Yasui reoperation risk compares favorably.

Surgically induced heart block is an additional risk that is encountered in the Yasui procedure. This complication occurred in 2 patients in our series, both of whom subsequently required insertion of a permanent pacemaker. The risk of surgically induced heart block is avoided in
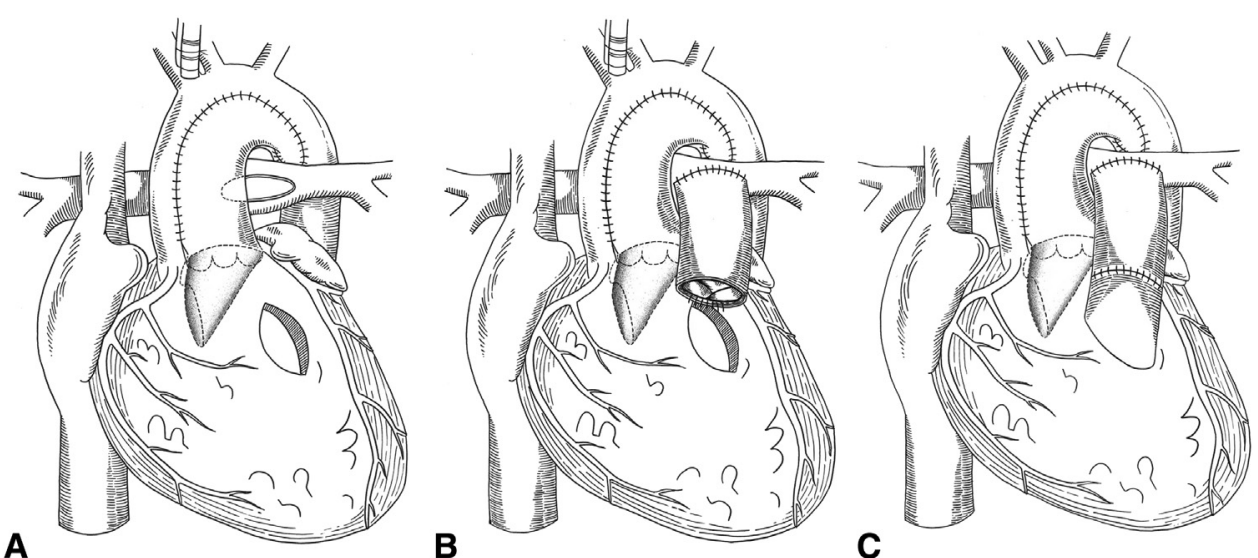

FIGURE 2. A, Pericardial patch channeling the VSD to the pulmonary valve. B, Aortic allograft conduit placed from the right ventricle to the confluence of the pulmonary arteries. C, Completed Yasui. An allograft patch was used to augment the proximal connection of the allograft valved conduit to the right ventricle. Illustrations created by Erin Anne Mainwaring. 
TABLE 2. Conduit sizes

\begin{tabular}{lrc}
\hline Patient no. & Initial conduit size & Second conduit size \\
\hline 1 Stage & 9 & \\
1 & 9 & - \\
2 & 9 & 17 \\
3 & 8 & - \\
4 & 10 & - \\
5 & 11 & 20 \\
6 & 9 & 18 \\
7 & 10 & 15 \\
8 & 11 & 19 \\
9 & 9 & - \\
10 & 11 & - \\
11 & 8 & 16 \\
12 & 11 & - \\
13 & 9 & 15 \\
14 & 12 & 17 \\
15 & & \\
2 Stage & 16 & 25 \\
16 & 8 & - \\
17 & 23 & 13 \\
18 & & \\
\hline
\end{tabular}

patients after a single-ventricle pathway, because the need for intracardiac procedures near the conduction system is minimized. However, the incidence of late arrhythmias after Fontan completion have been well chronicled, and thus this may be a tradeoff between early and late risk for pacemaker therapy.

One unanswered controversy is whether a single-stage or a 2-stage Yasui is more optimal. Both approaches have their advocates, with the literature evenly divided on this issue. The advantage of the single-stage approach is the normalization of the circulation, creating a 2-ventricle system with fully saturated blood going to the systemic circulation. This approach also increases the interval to the next reoperation compared with an initial Norwood procedure. Disadvantages of the single-stage approach

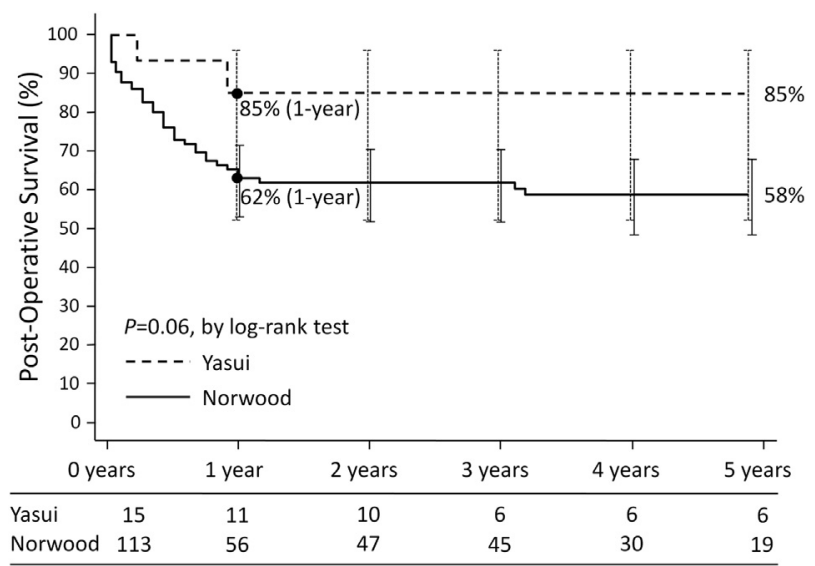

FIGURE 3. Kaplan-Meier survival curve comparing the Yasui and Norwood procedures.

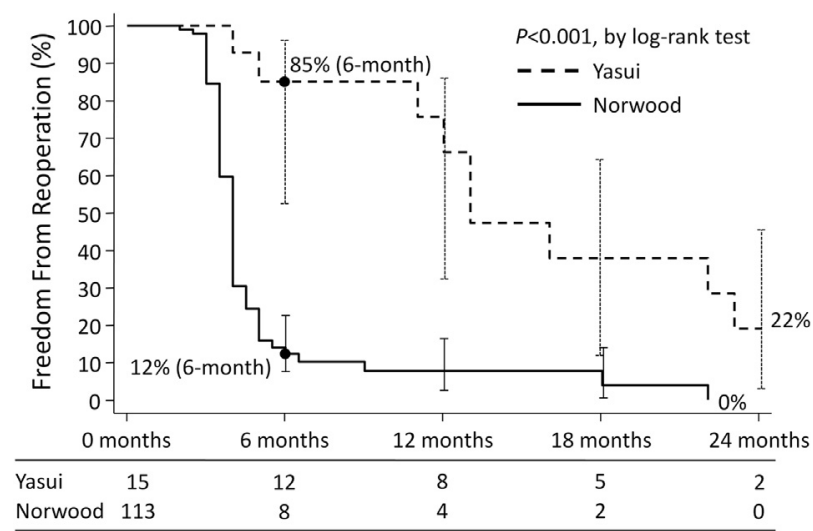

FIGURE 4. Freedom from reoperation comparing the Yasui and Norwood procedures.

include prolongation of the crossclamp and bypass times, insertion of small conduit sizes, and possibly a higher risk for surgically induced heart block. The 2-stage approach also has advocates, including a recent article from Nakano and colleagues. ${ }^{2}$ In this series, 11 of 17 patients had a staged approach, including a hybrid approach with a bilateral pulmonary artery band in 8 of the 11 patients. The advantages cited include performing the arch repair and intracardiac baffle in older and larger patients and the feasibility of inserting a larger right ventricle to pulmonary artery conduit. The disadvantages of this approach include the continuation of parallel circulation physiology with desaturated blood going to the systemic circulation. This physiology is associated with significant operative and interim mortality regardless of whether it is created with a hybrid approach or Norwood procedure. Arguably, this physiology may be better tolerated in patients with 2 well-formed ventricles, but there is no evidence in the literature to support this speculation. The literature on the 2-stage Yasui approach has not always made clear how many patients died after the first-stage hybrid or Norwood procedure and subsequently not included in the analysis of the 2-stage approach. This may result in an underestimation of the surgical mortality for the 2-stage approach. It has been our preference to perform a single-stage Yasui, because we believe that the normalization of the circulation will more than offset the disadvantages of this approach.

There are several surgical options that could be used for patients with critical aortic stenosis/atresia, an interrupted or hypoplastic aortic arch, VSD, and a normal-sized left ventricle. One such possibility would be a neonatal Ross/Konno in association with an aortic arch repair. ${ }^{22,23}$ This option would result in a 2-ventricle system, and thus confer the same physiologic advantages as the Yasui with respect to normalization of the circulation. The literature on the neonatal Ross/Konno combined with aortic arch repair would suggest that this procedure carries a prohibitively high mortality, most often attributed to errors 
in the patient selection process. In addition, the Ross/Konno option does not circumvent the issues associated with right ventricular outflow tract conduits. One additional operation that might be considered would be an aortic translocation (Nikaidoh) procedure. ${ }^{24,25}$ This procedure has been used primarily for the treatment of complex forms of transposition of the great arteries. However, even the advocates of the Nikaidoh procedure have not applied this operation to the anatomy amenable for a Yasui procedure. The relative merits of the Yasui procedure compared with alternative treatment strategies will be difficult to evaluate because of the relative rarity and heterogeneity of this heart defect.

\section{CONCLUSIONS}

This study was performed to evaluate the results of the Yasui compared with the Norwood procedure, because the Norwood is the most likely surgical alternative to the Yasui. The data demonstrate that the Yasui procedure demonstrated a lower mortality than the Norwood procedure, comparing results from a single institution during the same time period. The data also demonstrate that freedom from reoperation was superior in the Yasui cohort. These results provide confirmation that the establishment of 2-ventricle circulation has important physiologic consequences and confers significant midterm benefits compared with a single-ventricle circulation. On the basis of these data, we conclude that patients with anatomy amenable for a Yasui should undergo this complex procedure to derive the longer-term benefits of this approach.

\section{References}

1. Yasui H, Kado H, Nakano E, Yonenaga K, Mitani A, Tomita Y, et al. Primary repair of interrupted aortic arch and severe aortic stenosis in neonates. J Thorac Cardiovasc Surg. 1987;93:39-45.

2. Nakano T, Kado H, Tatewaki H, Hinokiyama K, Machida D, Ebuoka Y, et al. Yasui operation for adequate-sized ventricles with ventricular septal defect associated with aortic arch and left ventricular outflow tract obstructions. Eur J Cardiothorac Surg. 2014;45:e166-72.

3. Kanter KR, Kirshbom PM, Kogon BE. Biventricular repair with the Yasui operation (Norwood/Rastelli) for systemic outflow tract obstruction with two adequate ventricles. Ann Thorac Surg. 2012;93:1999-2006.

4. Krishna Moorthy PS, McGuirk SP, Jones TJ, Brawn WJ, Barron DJ. DamusRastelli procedure for biventricular repair of aortic atresia and hypoplasia. Ann Thorac Surg. 2007;84:142-6.

5. Nathan M, Rimmer D, del Nido PJ, Mayer JE, Bacha EA, Shin A, et al. Aortic atresia or severe left ventricular outflow tract obstruction with ventricular septal defect: results of primary biventricular repair in neonates. Ann Thorac Surg. 2006;82:2227-32.

6. Kanter KR. The Yasui operation. Operat Tech Thorac Cardiovasc Surg. 2010;15: 206-22.

7. Bove EL, Minich LL, Pridjian A, Lupinetti FM, Snider AR, Dick M, et al. The management of severe subaortic stenosis, ventricular septal defect, and aortic arch obstruction in the neonate. J Thorac Cardiovasc Surg. 1993;105:289-95.
8. Hickey EJ, Yeh T Jr, Jacobs JP, Calderone CA, Tchervenkov CI, McCrindle BW, et al. Ross and Yasui operations for complex biventricular repair in infants with critical left ventricular outflow tract obstruction. Eur J Cardiothorac Surg. 2010; 37:279-88.

9. Feinstein JA, Benson DW, Dubin AM, Cohen MS, Maxey DM, Mahle WT, et al. Hypoplastic left heart syndrome: current considerations and expectations. J Am Coll Cardiol. 2012;59(Suppl):S1-42.

10. Nasirov T, Mainwaring RD, Reddy VM, Sleasman JR, Margetson T, Hanley FL. Innominate artery cannulation and antegrade cerebral perfusion for aortic arch repair in infants and children. World J Pediatr Congenit Heart Surg. 2013;4: 356-61.

11. Grunkemeier GL, Jin R, Eijkemans JC, Takkenberg JJM. Actual and actuarial probabilities of competing risks: apples and lemons. Ann Thorac Surg. 2007; 83:1586-92.

12. Jegatheeswaran A, McCrindle BW, Blackstone EH, Jacobs ML, Lofland GK, Austin EH, et al. Persistent risk of subsequent procedures and mortality in patients after interrupted aortic arch repair: a Congenital Heart Surgeons' Society study. J Thorac Cardiovasc Surg. 2010;140:1059-75.

13. Jonas RA, Quaegebeur JM, Kirklin JW, Blackstone EH, Daicoff G. Outcomes in patients with interrupted aortic arch and ventricular septal defect: a multi-institutional study. J Thorac Cardiovasc Surg. 1994;107:1099-107.

14. Oosterhof T, Azakie A, Freedom RM, Williams WG, McCrindle BW. Associated factors and trends in outcomes of interrupted aortic arch. Ann Thorac Surg. 2004; 78:1696-702.

15. Salem MM, Starnes VA, Wells WJ, Acherman RJ, Chang RR, Luciani GB, et al Predictors of left ventricular outflow obstruction following single-stage repair of interrupted aortic arch and ventricular septal defect. Am J Cardiol. 2000;86: 1044-7.

16. McCrindle BW, Tchervenkov CI, Konstantinov IE, Williams WG, Neirotti RA, Jacobs ML, et al. Risk factors associated with mortality and interventions in 472 neonates with interrupted aortic arch: a Congenital Heart Surgeons Society study. J Thorac Cardiovasc Surg. 2005;129:343-50.

17. Morales DLS, Scully PT, Braud BE, Booth JH, Graves DE, Heinle JS, et al Interrupted aortic arch repair: aortic arch advancement without a patch minimizes arch reinterventions. Ann Thorac Surg. 2006;82:1577-84.

18. Hickey EJ, Caldarone CA, Blackstone EH, Williams WG, Yeh T Jr, Pizarro C, et al; Congenital Heart Surgeons' Society. Biventricular strategies for neonatal critical aortic stenosis: high mortality associated with early reintervention. $J$ Thorac Cardiovasc Surg. 2012;144:409-17.

19. Kirklin JW, Blackstone EH, Shimazaki Y, Maehara T, Pacifico AD, Kirklin JK, et al. Survival, functional status, and reoperation after repair of tetralogy of Fallot with pulmonary atresia. J Thorac Cardiovasc Surg. 1988; 96:102-16.

20. Tierney ESS, Gersony WM, Altmann K, Solowiejczyk DE, Bevilacqua LM, Khan C, et al. Pulmonary position cryopreserved homografts: durability in pediatric Ross and non-Ross patients. J Thorac Cardiovasc Surg. 2005;130: 282-6.

21. Poynter JA, Eghtesady P, McCrindle BW, Walters HL, Kirshbom PM, Blackstone EH, et al. Association of pulmonary conduit type and size with durability in infants and young children. Ann Thorac Surg. 2013;96: 1695-702.

22. Maeda K, Rizal RE, Lavrsen M, Malhotra SP, Akram SA, Davies R, et al Midterm results of the modified Ross/Konno procedure in neonates and infants. Ann Thorac Surg. 2012;94:156-63.

23. Shinkawa T, Bove EL, Hirsch JC, Devaney EJ, Ohye RG. Intermediate-term results of the Ross procedure in neonates and infants. Ann Thorac Surg. 2010; 89:1827-32.

24. Morell VO, Jacobs JP, Qunitessenza JA. Aortic translocation in the management of transposition of the great arteries with ventricular septal defect and pulmonary stenosis: results and follow-up. Ann Thorac Surg. 2005;79: 2089-92.

25. Yeh T Jr, Ramaciotti C, Leonard SR, Roy L, Nikaidoh H. The aortic translocation (Nikaidoh) procedure: midterm results superior to the Rastelli procedure. J Thorac Cardiovasc Surg. 2007;133:461-9. 